\title{
APLICAÇÃO DA ÁGUA DE DRENAGEM ÁCIDA DE MINA NA RECUPERAÇÃO DE SULFATO DE ALUMÍNIO EM LODO DE ETA
}

\author{
A. ORTH ${ }^{1}$, R. O. CORDELLA ${ }^{1}$ P. R. M. BARBOSA ${ }^{2}$, T. F. MIGUEL ${ }^{3}$, D. A. \\ MENEGARO $^{3}$, L. DOMINGUINI ${ }^{3}$, M. FERNANDES ${ }^{3}$ e E. SKORONSKI ${ }^{1}$ \\ ${ }^{1}$ Universidade do Estado de Santa Catarina, Departamento de Engenharia Ambiental \\ ${ }^{2}$ Carbonífera Criciúma, Departamento de Pesquisa e Desenvolvimento \\ ${ }^{3}$ Instituto Federal de Educação Tecnológica de Santa Catarina \\ E-mail para contato: skoronski@ cav.udesc.br
}

\begin{abstract}
RESUMO - Neste trabalho foi estudada a aplicação da água de drenagem ácida de mina (DAM) na recuperação de sulfato de alumínio em lodo de ETA. Foi utilizada uma DAM com concentração de sulfato de aproximadamente $13.000 \mathrm{mg} / \mathrm{L}$, ferro igual a $3400 \mathrm{mg} / \mathrm{L}$ e $\mathrm{pH}$ igual a 2,3. O lodo de ETA apresentou concentração de alumínio igual a 1,2 \% (m/m base seca) e $1,3 \%$ de ferro $(\mathrm{m} / \mathrm{m}$ base seca). As variáveis consideradas no processo de extração foram o tempo de contato entre os resíduos e a porcentagem de excesso de sulfato na solução. Os resultados apontaram que um tempo de 28 minutos e uma porcentagem de excesso de sulfato de $100 \%$ são condições otimizadas que permitem a remoção de 96,67 \% de alumínio do lodo da ETA para a solução formada (sulfato de alumínio e sulfato de ferro). O coagulante obtido foi aplicado no tratamento da água do rio Caveiras (Lages/SC). Os resultados apontaram uma redução da cor de 25,9 para 0,8 uC e de turbidez de 5 para 0 uT.
\end{abstract}

\section{INTRODUÇÃO}

O gerenciamento de lodos em estação de tratamento de água (ETA) é uma atividade bastante importante sob o ponto de vista de gestão ambiental destas estações, sobretudo quando se leva em conta os impactos causados por estas atividades ao meio ambiente (Richter e Netto, 2000; Nunes, 2001). O lançamento direto de lodos de ETA em água é uma atividade bastante comum na realidade das ETA's nacionais, desafiando assim a busca por metodologias de gerenciamento de lodo de ETA que apresentem viabilidade técnica e econômica para implementação.

Dentre as várias metodologias que consideram o gerenciamento dos lodos de ETA (Cordeiro, 1999; Realli et al., 1999; Oliveira et al., 2004), a recuperação do sulfato de alumínio com ácido sulfúrico possui grande atratividade por minimizar o custo de aquisição de coagulante a partir de fonte externa ao mesmo tempo em que evita o lançamento intenso de íons alumínio ao meio ambiente (Masschelin, 1985; Brandão, 1998; Freitas et al., 2005). Embora o processo de recuperação de coagulante utilizando ácido sulfúrico seja conhecido, não existem estudos que envolvam a aplicação de resíduos como fonte de íons sulfato, substituindo assim o ácido sulfúrico empregado neste 


\section{9 a 22 de outubro de 2014 \\ Florianópolis/SC}

processo. Diversos trabalhos descrevem as características da água de drenagem ácida de mina (DAM) como uma fonte concentrada de íons sulfato, sendo que este fator apresenta-se como um problema para o gerenciamento ambiental das minas de carvão (Shinobe e Sracek, 1997; Mello e Abrahão, 1998; Blodau, 2006; Neves e Silva, 2007; Campaner e Silva, 2009). Este problemática está relacionado à dificuldade de remediação da DAM em termos de íons sulfato, trazendo como consequência o lançamento de efluente aos corpos receptores com concentração de sulfato de alumínio acima dos limites exigidos pelos órgãos ambientais (Trindade e Soares, 2004).

Diante deste contexto, o presente trabalho teve como objetivo estudar a aplicação da água de drenagem ácida de mina na recuperação de alumínio em lodo de ETA, de forma a gerar um coagulante que pudesse ser utilizado para a remoção de cor e turbidez no tratamento de água para abastecimento.

\section{MATERIAL E MÉTODOS}

\section{1. Água de drenagem ácida de mina e lodo de ETA utilizados}

A DAM utilizada neste trabalho apresentou concentrações de íons sulfato igual a $12.800 \mathrm{mg} / \mathrm{L}$ e ferro total igual a $3.400 \mathrm{mg} / \mathrm{L}$, sendo a concentração de alumínio desprezível frente à ordem de grandeza das duas espécies químicas anteriormente citadas. Este resíduo é produzido em larga escala na região carbonífera de Criciúma, sendo que seu tratamento envolve normalmente a remoção de substâncias suspensas e de relativa capacidade de precipitação como íons de ferro e manganês. No entanto, íons sulfato por serem altamente solúveis persistem na água após o tratamento da DAM, sendo lançado diretamente aos corpos receptores com concentrações elevadas.

O lodo da ETA foi obtido junto à estação da Samae no município de Orleans. Este lodo apresentou uma umidade de $75 \%$, concentração de alumínio igual a $1,2 \%(\mathrm{~m} / \mathrm{m})$ em base seca e concentração de ferro igual a $1,3 \%(\mathrm{~m} / \mathrm{m})$ em base seca. Este resíduo foi coletado no leito de secagem da estaçãa. Este lodo é gerado no tratamento de água em uma estação convencional, que utiliza policloreto de alumínio (PAC) como coagulante. O manancial onde a água é coletada apresenta elevadas concentrações de ferro em sua composição, sendo que este metal é removido da água no processo de tratamento sendo posteriormente agregado ao lodo durante o tratamento.

\subsection{Processo de obtenção do coagulante}

Para a extração do alumínio presente no lodo da ETA com a DAM, inicialmente foi realizada a secagem do lodo em estufa a $105{ }^{\circ} \mathrm{C}$. Em seguida o lodo seco teve seu tamanho de partícula reduzido por maceração manual, até as partículas apresentarem caráter visual homogêneo. Este material foi misturado com $100 \mathrm{~mL}$ de DAM, de forma que a massa de lodo seco e moído adicionada à DAM foi variada para gerar diferentes quantidades de excesso de sulfato em relação ao valor estequiométrico requerida para formação do sulfato de alumínio, conforme a Equação 1.

$$
2 \mathrm{Al}^{+3}+3 \mathrm{SO}_{4}^{-2} \stackrel{\mathrm{H}_{2} \mathrm{O}}{\longrightarrow} \mathrm{Al}_{2}\left(\mathrm{SO}_{4}\right)_{3}
$$


Além desta variável, o tempo de extração foi considerado nos experimentos. A mistura formada foi mantida em agitação orbitalar em um shaker a $25^{\circ} \mathrm{C}$, com rotação de $200 \mathrm{rpm}$. A Tabela 1 apresenta o planejamento experimental utilizado neste trabalho. O planejamento envolveu 2 variáveis e dois fatores, além de triplicata do ponto central e adição de ponto rotacional. Ao todo foram realizados 11 experimentos. Como respostas dos testes, foram analisadas as concentrações de ferro, alumínio e sulfato no líquido sobrenadante. As análises foram realizadas de forma colorimétrica em um fotômetro (Spectroquant da MERCK), empregando o método para análise de sulfato (método 14564), alumínio (método 14825) e ferro total (método 14549).

\subsection{Ensaios de tratabilidade}

Nesta etapa, amostras de água foram coletadas no rio Caveiras, próxima ao ponto de captação da empresa concessionária de saneamento, no município de Lages/SC. Foram realizados ensaios de Jar Test variando a dosagem de sulfato $\left(0\right.$ a $\left.60 \mathrm{mg} \cdot \mathrm{L}^{-1}\right)$, tempo de mistura rápida de 1 minutos, gradiente de velocidade da mistura rápida de $200 \mathrm{~s}^{-1}$, tempo de floculação fixo em 30 minutos e gradiente de velocidade da floculação igual a $70 \mathrm{~s}^{-1}$. A avaliação do processo de tratabilidade foi realizada pela medida da cor, turbidez e sólidos suspensos presentes no sobrenadante obtido e também a velocidade de sedimentação do lodo, que foi realizada em cone IMHOFF. As medidas de cor, turbidez e sólidos suspensos foram determinadas por espectrofotometria no fotômetro (Spectroquant MERCK), empregando os métodos 32, 77 e 182, respectivamente. As concentrações de alumínio, ferro e sulfato foram determinadas colorimetricamente pelos métodos anteriormente descritos. Os valores foram comparados com os limites máximos sugeridos pela portaria do ministério da saúde $\mathrm{n}^{\circ}$ 2914 de 2011.

\section{RESULTADOS E DISCUSSÃO}

\subsection{Processo de obtenção do coagulante}

Os resultados obtidos após a extração do alumínio presente no lodo da ETA com a DAM são apresentados na Tabela 1 .

Tabela 1 - Resultados obtidos para os experimentos de extração do lodo da ETA. Na Tabela são apresentados os níveis reais da variáveis utilizados no experimento. Temperatura de $25{ }^{\circ} \mathrm{C}$ e rotação de $200 \mathrm{rpm}$.

\begin{tabular}{|c|c|c|c|c|c|c|c|}
\hline Teste & $\begin{array}{c}\text { Massa lodo } \\
\text { seco (g) }\end{array}$ & $\begin{array}{c}\text { Volume de } \\
\text { DAM (mL) }\end{array}$ & $\begin{array}{c}\text { Excesso } \\
\mathrm{SO}_{4}^{-2}(\%)\end{array}$ & Tempo (min) & $\begin{array}{c}\text { Extração } \\
\text { de } \\
\text { alumínio } \\
(\%)\end{array}$ & $\begin{array}{c}\mathrm{Fe} \\
\text { total } \\
(\mathrm{mg} / \mathrm{L})\end{array}$ & $\begin{array}{c}\mathrm{SO}_{4}{ }^{-2} \\
(\mathrm{mg} / \mathrm{L})\end{array}$ \\
\hline 1 & 14,70 & 100,00 & $36(-1)$ & $28,00(-1)$ & 30,61 & 3,14 & 12800 \\
\hline
\end{tabular}




\begin{tabular}{|c|c|c|c|c|c|c|c|}
\hline 2 & 14,70 & 100,00 & $36(-1)$ & $88,00(+1)$ & 23,81 & 3,15 & 12800 \\
\hline 3 & 10,00 & 100,00 & $100(+1)$ & $28,00(-1)$ & 96,67 & 2,37 & 12800 \\
\hline 4 & 10,00 & 100,00 & $100(+1)$ & $88,00(+1)$ & 50,00 & 2,64 & 12800 \\
\hline 5 & 16,40 & 100,00 & $22(-1,41)$ & $60,00(0)$ & 42,68 & 3,33 & 12800 \\
\hline 6 & 9,40 & 100,00 & $113(+1,41)$ & $60,00(0)$ & 42,55 & 2,33 & 12800 \\
\hline 7 & 11,90 & 100,00 & $68(0)$ & $15,00(-1)$ & 43,42 & 2,75 & 12800 \\
\hline 8 & 11,90 & 100,00 & $68(0)$ & $105,00(+1)$ & 50,42 & 2,73 & 12800 \\
\hline 9 & 11,90 & 100,00 & $68(0)$ & $60,00(0)$ & 50,42 & 2,73 & 12800 \\
\hline 10 & 11,90 & 100,00 & $68(0)$ & $60,00(0)$ & 39,22 & 2,63 & 12800 \\
\hline 11 & 11,90 & 100,00 & $68(0)$ & $60,00(0)$ & 50,42 & 2,6 & 12800 \\
\hline
\end{tabular}

Os resultados apontam que com um excesso de $100 \%$ de sulfato é possível remover 96,67\% do alumínio presente no lodo da ETA em 28 minutos de contato. A solução obtida apresentou concentração de sulfato igual a $12.800 \mathrm{mg} / \mathrm{L}$, concentração de alumínio igual a $1.160 \mathrm{mg} / \mathrm{L}$ e concentração de ferro total igual a $3.170 \mathrm{mg} / \mathrm{L}$. Esta condição foi considerada para realização dos ensaios de tratabilidade em Jar Test. Estes valores apontam que o coagulante formado possuía sulfato de alumínio e sulfato de ferro. Ambos são utilizados com frequência em sistemas de tratamento de água. Neste sentido, o lodo gerado se encontra praticamente isento de alumínio, permitindo uma destinação deste lodo sem os problemas inerentes à presença deste metal na composição.

Observa-se que a concentração de sulfato permanece constante no coagulante obtido, uma vez que o volume de DAM é o mesmo em todos os testes e somente a quantidade de lodo adicionada é variável, apresentando baixa concentração de sulfato de forma a não modificar a concentração da mistura. Foi aplicado um modelo matemático de $2^{\mathrm{a}}$ ordem considerando os efeitos lineares e quadráticos de cada fator e também a combinação linear entre eles. Os efeitos lineares da concentração de sulfato e do tempo de processo foram as variáveis significativas neste processo, influenciando de forma positiva a extração de alumínio.

\subsection{Ensaios de Tratabilidade}

Para os ensaios de tratabilidade foram adicionados volumes de solução de forma que a concentração de sulfato se situasse entre 0 e $60 \mathrm{mg} / \mathrm{L}$. Os resultados são apresentados na Tabela 2.

Tabela 2 - Ensaios de tratabilidade com o coagulante obtido do lodo da ETA e da DAM. A amostra bruta representa a amostra onde não foi adicionado sulfato. Os resultados referem-se à realização de três ensaios de Jar Test e os dados são apresentados em forma de média.

\begin{tabular}{|l|l|l|l|l|l|}
\hline Concentração & Cor & Turbidez & Sólidos & Ferro & Aluminio \\
\hline
\end{tabular}




\begin{tabular}{|c|c|c|c|c|c|}
\hline $\begin{array}{c}\text { de sulfato } \\
(\mathrm{mg} / \mathrm{L})\end{array}$ & $(\mathrm{uC})$ & $(\mathrm{uT})$ & $\begin{array}{c}\text { Suspensos } \\
(\mathrm{mg} / \mathrm{L})\end{array}$ & $(\mathrm{mg} / \mathrm{L})$ & $(\mathrm{mg} / \mathrm{L})$ \\
\hline 10 & 4.3 & 0 & --- & 0.6 & 0.12 \\
\hline 20 & 2.9 & 0 & --- & 1.11 & 0.10 \\
\hline 30 & 3.5 & 0 & --- & 1.68 & 0.13 \\
\hline 40 & 4.9 & 0 & --- & 2.37 & 0.19 \\
\hline 50 & 5.4 & 0 & --- & 3.09 & 0.55 \\
\hline 60 & 5.7 & 0 & --- & 3.76 & 0.76 \\
\hline Bruta & 25.9 & 5 & 6 & 0.44 & 0.16 \\
\hline $\begin{array}{c}\text { LMP } \\
2914 / 2011\end{array}$ & 15 & 5 & --- & 0,30 & 0,20 \\
\hline
\end{tabular}

A amostra bruta apresentou cor e turbidez acima dos limites máximos permitidos pela portaria 2914/2011 do ministério da Saúde. Os valores recomendados pela portaria são 15 uC e 0,5 uT. A concentração de ferro está acima do recomendado pela mesma referência (LMP igual a 0,3 mg/L) e o alumínio está abaixo do limite (LMP igual a $0,2 \mathrm{mg} / \mathrm{L}$ ). A adição de sulfato de alumínio na concentração de $20 \mathrm{mg} / \mathrm{L}$ consegue adequar a cor e a turbidez aos valores recomendados e também diminui para $0,10 \mathrm{mg} / \mathrm{L}$ a concentração de alumínio. No entanto, a concentração de ferro aumenta para $1,11 \mathrm{mg} / \mathrm{L}$. Este aumento está relacionado ao fato de a DAM apresentar ferro nas formas de íons ferrosos e íons férricos. Uma vez que o $\mathrm{pH}$ da DAM encontra-se na faixa de 2-3, estas espécies encontram-se dissolvidas e são incorporadas ao coagulante e consequentemente à água em função do tratamento. Neste sentido, foi realizado mais uma bateria de testes com o objetivo de converter os íons ferrosos em íons férricos e assim promover a sua precipitação, permitindo a sua remoção no lodo gerado durante o tratamento. Neste sentido, os testes anteriores foram repetidos com a adição de hipoclorito de sódio (2,5\%), em solução no momento da adição do coagulante. A concentração de cloro livre adicionado em relação à concentração de ferro foi igual a 0,62:1, em base mássica. Os resultados são apresentados na Tabela 3.

Tabela 3 - Ensaios envolvendo a adição de hipoclorito de sódio (2,5\%) junto com o coagulante obtido da DAM e lodo de ETA. Os resultados referem-se à realização de três ensaios de Jar Test e os dados são apresentados em forma de média. 


\begin{tabular}{|c|c|c|c|c|}
\hline $\begin{array}{c}\text { Concentração } \\
\text { de sulfato } \\
(\mathrm{mg} / \mathrm{L})\end{array}$ & $\begin{array}{c}\text { Cor } \\
(\mathrm{uC})\end{array}$ & $\begin{array}{c}\text { Turbidez } \\
(\mathrm{uT})\end{array}$ & $\begin{array}{c}\text { Sólidos } \\
\text { Suspensos } \\
(\mathrm{mg} / \mathrm{L})\end{array}$ & $\begin{array}{c}\text { Ferro } \\
(\mathrm{mg} / \mathrm{L})\end{array}$ \\
\hline 5 & 18.3 & 2 & 0 & 0.80 \\
\hline 10 & 1.6 & 0 & 1 & 0.11 \\
\hline 15 & 0.8 & 0 & 0 & 0.04 \\
\hline 20 & 4.4 & 0 & 0 & 0.16 \\
\hline 30 & 3.4 & 0 & 0 & 0.12 \\
\hline 40 & 2.0 & 0 & 0 & 0.13 \\
\hline Bruta & 25.9 & 5 & 6 & 0.44 \\
\hline $\begin{array}{c}\text { LMP } \\
2914 / 2011\end{array}$ & 15 & 5 & --- & 0,30 \\
\hline
\end{tabular}

Os resultados apontam que a adição de cloro possibilita a remoção de ferro, possivelmente pela conversão dos íons ferrosos em íons férricos que são menos solúveis e são removidos do sistema juntamente com o lodo gerado. Além disto, a cor nos testes realizados foi menor que nos testes apresentados na Tabela 2, provavelmente pela remoção de matéria orgânica natural da água e/ou a remoção de ferro do meio. Durante a realização dos testes, o pH foi mantido na faixa de 6 a 7, com a adição de solução $0,1 \mathrm{~mol} / \mathrm{L}$ de $\mathrm{NaOH}$. A velocidade de sedimentação do lodo no teste com $15 \mathrm{mg} / \mathrm{L}$ de sulfato (Tabela 3 ) foi de $1,78 \mathrm{~cm} / \mathrm{min}$.

\section{CONCLUSÃO}

Os resultados obtidos com a realização deste trabalho demonstraram que é possível extrair alumínio de lodo de ETA utilizando DAM como fonte de íons sulfato e produzir um coagulante que reduz cor, turbidez e alumínio existentes na água bruta, e estudos posteriores devem ser feitos para avaliar se existe a possibilidade de agregar substâncias que possam comprometer o tratamento convencional da água. Novos testes devem ser feitos de forma que a concentração de ferro na solução seja controlado de forma a não afetar a qualidade da água obtida.

\section{REFERÊNCIAS}

BLODAU, C. A review of acidity generation and consumption in acidic coal mine lakes and their watersheds. Sci. Total Environ., v. 369, p. 3017-332, 2006.

BRANDÃO, J. T. Recuperação de coagulantes através de solubilização pela via ácida de lodos de diversas ETAs no Espírito Santo com posterior reutilização no tratamento de águas para abastecimento e águas residuárias. 1998, 140 p. Dissertação (Mestrado). Universidade Federal do Espírito Santo. 
CAMPANER, V. P.; SILVA, W. L. Processos físico-quimicos em drenagem ácida de minas em mineração de carvão no sul do Brasil. Quim. Nova, v. 32, p. 146-152, 2009.

CORDEIRO, J. S. Noções gerais de tratamento e disposição final de lodos de estações de tratamento de água. PROSAB, Cap. 5, 1999.

FREITAS, J. G; FERREIRA FILHO, S. S; PIVELI, R. P; Viabilidade técnica e econômica da regeneração de coagulantes a partir de lodos de estações de tratamento de água. Eng. Sanit. Ambient., v.10, p.137-145, 2005.

MASSCHELIN, W. J., DEVLEMINCK, R., GENOT, J. The feasibility of coagulant recycling by alkaline reation of aluminium hidroxide sludges. Water Res. v.19, p.1363-1368, 1985.

MELLO, J. W. V; ABRAHÃO, W. A. P. Geoquímica da drenagem ácida. In: Recuperação de áreas degradadas. Viçosa, 1998.

MINISTÉRIO DA SAÚDE, PORTARIA N 2.914, de 12 de Dezembro de 2011. Dispõe sobre os procedimentos de controle e de vigilância da qualidade da água para consumo humano e seu padrão de potabilidade.

NEVES, C. A. R. e SILVA, L. R. Universo da Mineração Brasileira. Brasília: Departamento Nacional de Produção Mineral - DNPM, 2007.

NUNES, J. A. Tratamento físico-químico de águas residuárias industriais. Aracajú: Editora Triunfo Ltda, 2001.

OLIVEIRA, E. M. S.; MACHADO, S. Q.; HOLANDA, J. N. F. Caracterização de resíduo (lodo) proveniente de estação de tratamento de águas visando sua utilização em cerâmica vermelha. Cerâmica, v. 50, p. 324-330, 2004.

REALI, M. A. P. Principais características quantitativas e qualitativas do lodo de ETAs. In: REALI, M.A.P (Coord.). Noções gerais de tratamento e disposição final de lodos de estações de tratamento de água. Rio de Janeiro: ABES, 1999.

RICHTER, C. A. e NETTO, J. M. A. Tratamento de água - Tecnologia atualizada. São Paulo: Editora Edgard Blücher Ltda, 2000.

SHINOBE, A.; SRACEK, A. Drenagem ácida e seu impacto ambiental. Saneamento Ambiental, v. 48, p.20-2 2, 1997.

TRINDADE, R. B. E.; SOARES P. S. M. Tecnologia de Sistemas Passivos para o Tratamento de Drenagem Ácida De Minas. Rio de janeiro: CETEM/MCT, 2004. 